\title{
ZMIENNOŚĆ OBCIĄŻENIA CIEPLNEGO SYSTEMU GRZEWCZEGO SZKLARNI Z EKRANEM TERMOIZOLACYJNYM
}

\begin{abstract}
W pracy przedstawiono wyniki badań i analiz zużycia energii w wolnostojącej szklarni z ekranem termoizolacyjnym. Celem tych badań była analiza zmienności obciążenia cieplnego w szklarni z ruchomym ekranem termoizolacyjnym. Analizy wykonano w oparciu o pomiary parametrów klimatu, mikroklimatu szklarni, zużycia energii oraz parametrów opisujących funkcjonowanie wyposażenia technicznego szklarni. Według analiz średni miesięczny współczynnik obciążenia zawiera się w zakresie od 9\% do 69\%. Przedstawiono miesięczną i dobową strukturę zużycia energii w badanej szklarni z ekranem i bez ekranu. W analizach zmienności obciążenia cieplnego systemu grzewczego szklarni z ekranem termoizolacyjnym zaleca się korzystać z danych zużycia energii lub zapotrzebowania na ciepło.
\end{abstract}

Słowa kluczowe: szklarnia, ekran termoizolacyjny, system grzewczy, zużycie ciepła, obciążenie cieplne

\section{Wprowadzenie}

Zmienność obciążenia cieplnego systemu grzewczego szklarni jest uwarunkowana wpływem zewnętrznych czynników klimatycznych na mikroklimat szklarni, a także funkcjonowaniem wyposażenia technicznego: ruchomego ekranu termoizolacyjnego, wietrzników. Ekrany termoizolacyjne zmniejszają zużycie ciepła w szklarni, ale nie zmniejszają zapotrzebowania na moc cieplną. Zapotrzebowanie szklarni na paliwo określa się zwykle na podstawie uporządkowanego wykresu obciążeń cieplnych lub w oparciu o średnioroczny współczynnik wykorzystania maksymalnej mocy grzewczej.

W artykule postanowiono zaprezentować wyniki badań zmienności obciążenia cieplnego szklarni na podstawie pomiarów przeprowadzonych w całorocznie eksploatowanej szklarni. Wykonanie tych analiz było możliwe $\mathrm{z}$ uwagi na kompleksowość przeprowadzanych pomiarów, jak również ich kompletność $\mathrm{z}$ uwagi na niewielkie braki $\mathrm{w}$ zarejestrowanych danych. Pomiary dotyczyły nie

\footnotetext{
${ }^{1}$ Sławomir Grabarczyk, Politechnika Warszawska, Filia w Płocku, Instytut Budownictwa, ul. Łukasiewicza 17, 09-400 Płock; tel. 243672114; slawekg@pw.plock.pl
} 
źródła ciepła a budynku szklarni, a zatem zaprezentowane wyniki stanowią obciążenie cieplne systemu grzewczego tego obiektu.

\section{Opis procedury badawczej}

\subsection{Obiekt badań}

Ekrany termoizolacyjne instalowane wewnątrz szklarni zmieniają właściwości termoizolacyjne przegrody zewnętrznej (rys. 1). Skutkuje to zmianą zapotrzebowania na energię cieplną nie tylko zależnie od pory roku, pory dnia ale także stanu zamknięcia ekranu termoizolacyjnego. W analizach zwrócono szczególną uwagę na okres funkcjonowania szklarni z dodatkową osłoną, co ma miejsce w porze nocnej, kiedy zamknięty ekran zmniejsza straty ciepła. Typowy schemat funkcjonowania ekranu w szklarni przedstawiono na rys. 2.

Przedmiotem analiz jest szklarnia wolnostojąca z pojedynczym pokryciem zlokalizowana w Skierniewicach. Ogólny współczynnik przenikania ciepła przegrody zewnętrznej wynosi $6,68 \mathrm{~W} /\left(\mathrm{m}^{2} \mathrm{~K}\right)$, natomiast w warunkach funkcjonowania ekranu termoizolacyjnego jako dodatkowej osłony jego wartość zmniejsza się do 4,66 W/( $\left.\mathrm{m}^{2} \mathrm{~K}\right)$ [1]. Ogólny współczynnik przenikania ciepła, charakterystyczny dla przegród szklarni, określono na podstawie pomiarów zużycia ciepła w badanym obiekcie uwzględniając: materiał pokrycia, rodzaj systemu grzewczego i warunki przeprowadzania badań, zgodnie z literaturą [2].

Na przegrodach pionowych szklarni po stronie zewnętrznej przytwierdzono osłonę z folii pęcherzykowej. W szklarni zainstalowano ekran termoizolacyjny HS 787 zbudowany z włókniny akrylowo-poliestrowej z paskami aluminium. Energooszczędność, określająca w procentach ograniczenie strumienia strat ciepła przez przegrodę zewnętrzną szklarni w przypadku tego ekranu wynosi $50 \%$. Ekran HS 787 zainstalowano równolegle do ścian bocznych i poziomo na wysokości okapu. Charakterystykę badanej szklarni przedstawia tabela 1.

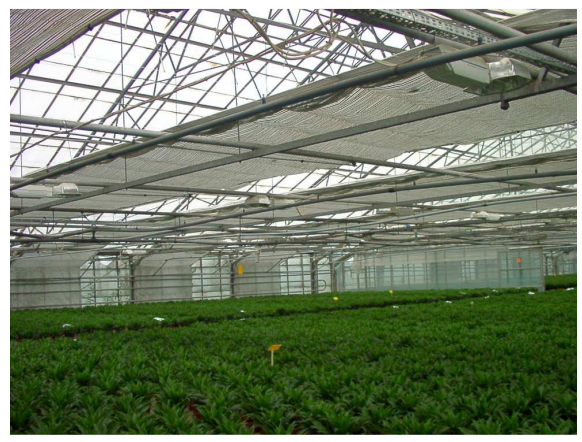

Rys. 1. Ekran termoizolacyjny HS 787 w szklarni

Fig. 1. Thermal screen type HS 787 inside greenhouse

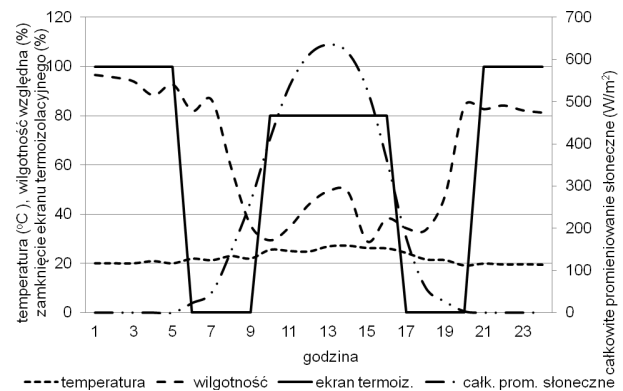

Rys. 2. Stan zamknięcia ekranu termoizolacyjnego w okresie jednego dnia

Fig. 2. Thermal screen position during one day 
Tabela 1. Charakterystyka szklarni

Table 1. Greenhouse description

\begin{tabular}{|l|c|c|}
\hline \multicolumn{1}{|c|}{ Wielkość } & Wartość & Jedn. \\
\hline Powierzchnia zabudowy szklarni & 1250 & $\mathrm{~m}^{2}$ \\
\hline Powierzchnia pokrycia szklarni & 1844,5 & $\mathrm{~m}^{2}$ \\
\hline Szerokość szklarni & 20,0 & $\mathrm{~m}$ \\
\hline Wysokość ściany bocznej szklarni & 2,2 & $\mathrm{~m}$ \\
\hline Długość szklarni & 62,5 & $\mathrm{~m}$ \\
\hline Kąt nachylenia połaci dachu & 27 & stopień \\
\hline Ogólny współczynnik przenikania ciepła szklarni bez / z ekranem & $6,68 / 4,66$ & $\mathrm{~W} /\left(\mathrm{m}^{2} \mathrm{~K}\right)$ \\
\hline Kubatura szklarni pod pokryciem ze szkła / pod ekranem & $6187,5 / 3518,8$ & $\mathrm{~m}^{3}$ \\
\hline
\end{tabular}

\subsection{Założenia do badań}

Określenie rzeczywistego obciążenia cieplnego systemu grzewczego szklarni wymagało przeprowadzenia pomiarów zużycia ciepła dostarczanego do szklarni - ciepłomierzem Aquatherm, rejestracji parametrów mikroklimatu i danych opisujących funkcjonowanie wyposażenia technicznego szklarni oraz klimatu zewnętrznego - systemem pomiarowym Volmatic. Przyjęto interwał czasowy pomiędzy pomiarami równy 10 minut.

\section{Metodyka i wyniki badań}

W efekcie przeprowadzonych badań uzyskano kompletne dane pomiarowe z okresu od 15 maja 2005 do 14 maja 2006 r. Wyniki pomiarów zostały zagregowane do zbiorów zawierających dane zarejestrowane $\mathrm{z}$ interwałem czasowym 10 min. i ogólnej liczbie rekordów równej 52560, a także zbiorów z interwałem równym jednej godzinie i łącznej liczbie rekordów wynoszącej 8760.

\section{Analiza wyników}

W oparciu o przygotowane zbiory danych pomiarowych sporządzono uporządkowany wykres występowania temperatury zewnętrznej dla danej lokalizacji i okresu badań (rys. 3). W okresie przeprowadzania pomiarów stwierdzono występowanie bardzo wysokich temperatur powietrza zewnętrznego, osiągających w lipcu $36,8^{\circ} \mathrm{C}$, natomiast w styczniu bardzo niskich temperatur zewnętrznych dochodzących do $-28^{\circ} \mathrm{C}$. Uporządkowany wykres rzeczywistych obciążeń systemu grzewczego zbudowano w oparciu o pomiary zużycia ciepła, a nie obserwacje mocy chwilowych $\mathrm{z}$ uwagi na okresowe dostarczanie strumienia ciepła przez system grzewczy. Wyniki zaprezentowano z podziałem na okresy eksploatacji szklarni z ekranem termoizolacyjnym i bez ekranu (rys. 4). 


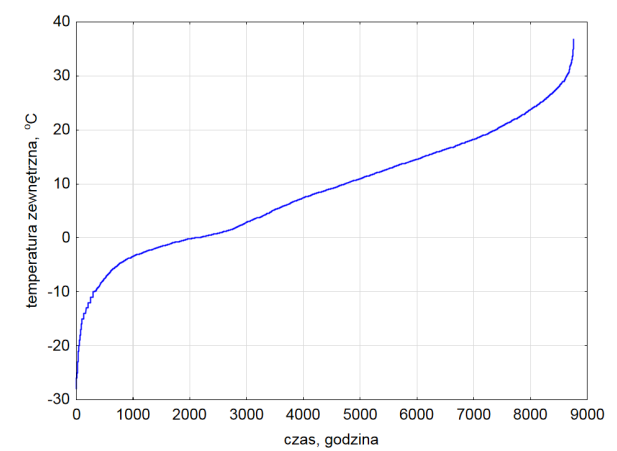

Rys. 3. Uporządkowany wykres temperatury zewnętrznej

Fig. 3. Systematic graph for outside air temperature

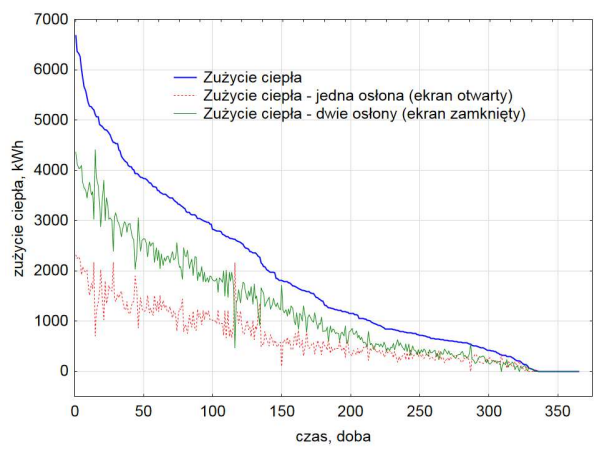

Rys. 4. Uporządkowany wykres obciążeń cieplnych systemu grzewczego szklarni

Fig. 4. Systematic graph for heating load in greenhouse

Wyniki analiz zmienności obciążeń cieplnych systemu grzewczego pozwalają określić, że w miesiącach zimniejszych średnie miesięczne zużycie ciepła w czasie eksploatacji szklarni $\mathrm{z}$ ekranem jest ponad dwukrotnie większe niż w okresie gdy ekran jest otwarty. W miesiącach najcieplejszych różnice te zanikają i w szklarni zużywane są porównywalne ilości ciepła w porze dnia i nocy.

Analizę występowania temperatury w szklarni w przekroju całego roku przedstawiono z podziałem na porę nocną - bez zysków słonecznych oraz przy całkowitym promieniowaniu słonecznym padającym na płaszczyznę poziomą $I_{c}>0 \mathrm{~W} / \mathrm{m}^{2}$ (tabela 2). Ważne jest to głównie z powodu funkcjonowania ekranu otwieranego już przy minimalnej dawce natężenia światła.

Tabela 2. Średnie miesięczne temperatury w szklarni podczas pory dnia i nocą. Oznaczenia: $t_{\text {wew }}$ - temperatura w szklarni $\left[{ }^{\circ} \mathrm{C}\right], I_{c}$ - całkowite promieniowanie słoneczne $\left[\mathrm{W} / \mathrm{m}^{2}\right]$

Table 2. Mean monthly temperatures in greenhouse during daytime and during the night. Symbols: $t_{\text {wew }}-$ greenhouse temperature $\left[{ }^{\circ} \mathrm{C}\right], I_{c}-$ global solar radiation $\left[\mathrm{W} / \mathrm{m}^{2}\right]$

\begin{tabular}{|c|c|c|c|c|c|c|c|c|c|c|c|c|}
\hline Miesiąc & Sty & Lut & Mar & Kwi & Maj & Cze & Lip & Sie & Wrz & Paź & Lis & Gru \\
\hline $\boldsymbol{t}_{\text {wew }} ; \boldsymbol{I}_{\boldsymbol{c}}=\mathbf{0}$ & 19,0 & 17,5 & 14,1 & 15,9 & 17,0 & 15,6 & 21,6 & 21,9 & 22,1 & 21,2 & 19,2 & 18,4 \\
\hline $\boldsymbol{t}_{\text {wew }} ; \boldsymbol{I}_{\boldsymbol{c}}>\mathbf{0}$ & 18,5 & 18,4 & 19,0 & 18,8 & 25,3 & 23,7 & 27,5 & 26,3 & 26,0 & 22,6 & 19,5 & 18,0 \\
\hline
\end{tabular}

Analiza eksploatacji szklarni i jej systemu grzewczego w ciągu pełnego roku funkcjonowania, pozwoliła na określenie liczby godzin ogrzewania - tu wartości związanej bezpośrednio z dostarczeniem energii cieplnej, wykazanej na urządzeniu pomiarowym jakim jest ciepłomierz. W wyniku analiz stwierdzono, że w okresie 3425 godzin szklarnia funkcjonuje bez ogrzewania - czynnik grzejny nie jest dostarczany, a temperatura w szklarni przekracza wartość nastawy, a tym samym nie jest konieczne uzupełnianie strumieniem ciepła z systemu grzewczego (tabela 3 ). W okresie 5335 godzin, czyli prawie $61 \%$ czasu w roku, szklarnia wy- 
maga ogrzewania, przy czym 3461 godzin gdy ekran stanowi drugą przegrodę szklarni, natomiast 1874 godziny, gdy ekran zmienia swe położenie: jest w ruchu lub w stanie otwartym, bądź jest niecałkowicie zamknięty.

Tabela 3. Liczba godzin bez ogrzewania i liczba godzin ogrzewania szklarni z ekranem i bez ekranu termoizolacyjnego. Oznaczenia: $L_{g}$ - liczba godzin ogrzewania $[\mathrm{h}], L_{0}-$ liczba godzin braku ogrzewania [h], $N$ - liczba obserwacji (godzin)

Table 3. Number of hours with and without turning on heating system - greenhouse with and without thermal screen. Symbols: $L_{g}-$ numbers of hours with turning on heating system [h], $L_{0}-$ numbers of hours without turning on heating system [h], $N$ - number of observation (hours)

\begin{tabular}{|c|c|c|c|c|c|c|c|c|c|c|c|c|c|}
\hline \multicolumn{2}{|c|}{ Miesiąc } & Sty & Lut & Mar & Kwi & Maj & Cze & Lip & Sie & Wrz & Paź & Lis & Gru \\
\hline \multirow{2}{*}{$L_{0}$} & $N$ & 22 & 87 & 344 & 346 & 559 & 649 & 430 & 373 & 320 & 218 & 72 & 5 \\
\hline & $\%$ & 3,0 & 12,9 & 46,2 & 48,1 & 75,1 & 90,1 & 57,8 & 50,1 & 44,4 & 29,3 & 10,0 & 0,7 \\
\hline \multirow{2}{*}{$L_{g}$} & $N$ & 722 & 585 & 400 & 374 & 185 & 71 & 314 & 371 & 400 & 526 & 648 & 739 \\
\hline & $\%$ & 97,0 & 87,1 & 53,8 & 51,9 & 24,9 & 9,9 & 42,2 & 49,9 & 55,6 & 70,7 & 90,0 & 99,3 \\
\hline \multirow{2}{*}{$\begin{array}{c}L_{g} \\
\text { z ekranem }\end{array}$} & $N$ & 482 & 372 & 230 & 216 & 105 & 40 & 181 & 232 & 274 & 373 & 443 & 513 \\
\hline & $\%$ & 64,8 & 55,4 & 30,9 & 30,0 & 14,1 & 5,6 & 24,3 & 31,2 & 38,1 & 50,1 & 61,5 & 69,0 \\
\hline \multirow{2}{*}{$\begin{array}{c}L_{g} \\
\text { bez ekranu }\end{array}$} & $N$ & 240 & 213 & 170 & 158 & 80 & 31 & 133 & 139 & 126 & 153 & 205 & 226 \\
\hline & $\%$ & 32,3 & 31,7 & 22,8 & 21,9 & 10,8 & 4,3 & 17,9 & 18,7 & 17,5 & 20,6 & 28,5 & 30,4 \\
\hline
\end{tabular}

Zmienność obciążenia systemu grzewczego szklarni można wyrazić również wartością współczynnika maksymalnej mocy grzewczej $L F \mathrm{w}$ sezonie grzewczym lub w analizowanym okresie [3]. Współczynnik ten określa się na podstawie częstotliwości występowania temperatury zewnętrznej, co przekłada się na zmiany obciążenia cieplnego systemu grzewczego i określa z wzoru (1):

$$
L F=\frac{\sum_{i}^{N} \tau_{i}\left(t_{w e w}-\overline{t_{z e w, i}}\right)}{\tau_{g}\left(t_{w e w}-t_{z e w, \min }\right)}
$$

gdzie: $N$ - liczba obserwacji w analizowanym okresie,

$\tau_{i}$ - długość trwania przedziału czasowego,

$\tau_{g}$ - czas trwania sezonu grzewczego lub analizowanego okresu,

$t_{\text {wew }}$ - temperatura w szklarni,

$t_{z e w, \min }$ - minimalna temperatura na zewnątrz szklarni,

$\overline{t_{z e w, i}}-$ średnia temperatura powietrza na zewnątrz szklarni w przyjętym przedziale czasowym.

Średnioroczna wartość współczynnika maksymalnej mocy grzewczej, obliczona ze wzoru (1) wynosi 0,31 i została ustalona dla temperatury zewnętrznej $-20^{\circ} \mathrm{C}$, czyli projektowej temperaturze zewnętrznej w III strefie klimatycznej okresu zimowego. Analizę zmienności obciążenia systemu grzewczego szklarni 
wykonano także dla miesięcy analizowanego roku badań. Średnie miesięczne wartości współczynnika maksymalnej mocy grzewczej zawiera tabela 4.

Tabela 4. Średnia miesięczna wartości współczynnika maksymalnej mocy grzewczej $L F$

Table 4. Mean monthly Load Factor

\begin{tabular}{|c|c|c|c|c|c|c|c|c|c|c|c|c|}
\hline Miesiąc & Sty & Lut & Mar & Kwi & Maj & Cze & Lip & Sie & Wrz & Paź & Lis & Gru \\
\hline LF & 0,69 & 0,53 & 0,44 & 0,21 & 0,13 & 0,09 & 0,10 & 0,14 & 0,17 & 0,29 & 0,40 & 0,48 \\
\hline
\end{tabular}

Zmienność obciążenia systemu grzewczego szklarni waha się od 9-10\% w miesiącu czerwcu i lipcu do 69\% maksymalnej mocy grzewczej w miesiącu styczniu. Weryfikacja zmienności obciążenia systemu grzewczego, zwłaszcza w oparciu o pomiary mocy obliczeniowej jest trudna do oceny [4], dlatego pozostałe analizy wykonano w oparciu o pomiar rzeczywistego zużycia ciepła w szklarni z ekranem zmieniającym właściwości przegrody zewnętrznej.

Wyniki badań w szklarni z ekranem pozwoliły na określenie zależności zużycia ciepła od różnicy temperatur powietrza, zarówno w okresie funkcjonowania ekranu jako dodatkowej osłony (rys. 5) jak i w czasie gdy ekran był otwarty (rys. 6). Zależność jest silniejsza dla szklarni z ekranem, ponieważ dłuższy jest czas eksploatacji szklarni w miesiącach zimowych. Szklarnia z otwartym ekranem jest użytkowana w czasie gdy zyski słoneczne zmniejszają zużycie ciepła.

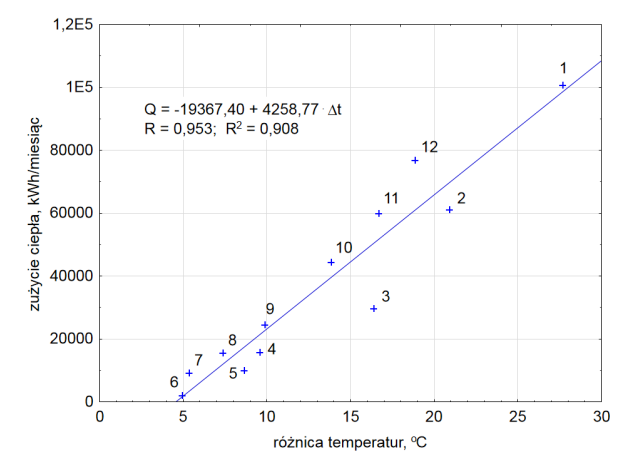

Rys. 5. Zużycie ciepła w szklarni z ekranem termoizolacyjnym w funkcji różnicy temperatur

Fig. 5. Energy consumption of greenhouse with thermal screen as function of different temperature

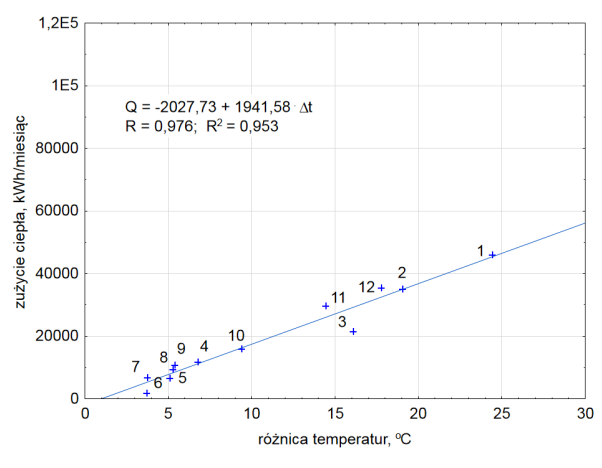

Rys. 6. Zużycie ciepła w szklarni z otwartym ekranem w funkcji różnicy temperatur

Fig. 6. Energy consumption of greenhouse without thermal screen as function of different temperature

Określone na podstawie badań zależności zużycia ciepła od różnicy temperatur pozwalają na uproszczone obliczenie zapotrzebowania na paliwo dla źródła ciepła w szklarni o zmiennych właściwościach przegrody, zakładając typowy schemat funkcjonowania ekranu termoizolacyjnego. Oczywiście taki scenariusz 
jest możliwy w obiekcie o zbliżonej wielkości i podobnych rozwiązaniach w zakresie ograniczenia strat ciepła.

Analiza zmienności obciążenia systemu grzewczego szklarni pozwala stwierdzić, że większa połowa obserwacji zużycia ciepła w miesiącach od maja do sierpnia jest zerowa. Wynika to z cykliczności dostarczania strumienia ciepła z systemu grzewczego i jego sterowania. Obserwacje zmienności obciążenia systemu grzewczego szklarni w przekroju dobowym, na podstawie zarejestrowanych danych z całego roku badań, wykazują znaczącą nierównomierność, zwłaszcza między godziną 6:00 a 15:00, kiedy różnice w zużyciu ciepła są czterokrotne. Analiza zmienności zużycia ciepła w przekroju godzinowym została zilustrowana dla przykładowych miesięcy na rys. 7 i 8, odpowiednio dla stycznia i lipca.

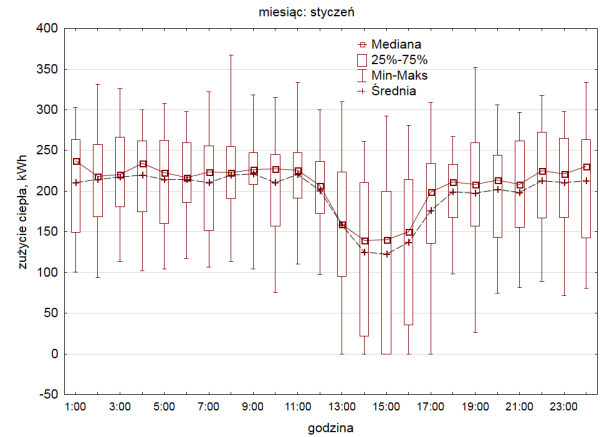

Rys. 7. Wykres ramka-wąsy dla zużycia ciepła w miesiącu styczniu

Fig. 7. Box and whiskers plot for energy consumption in January

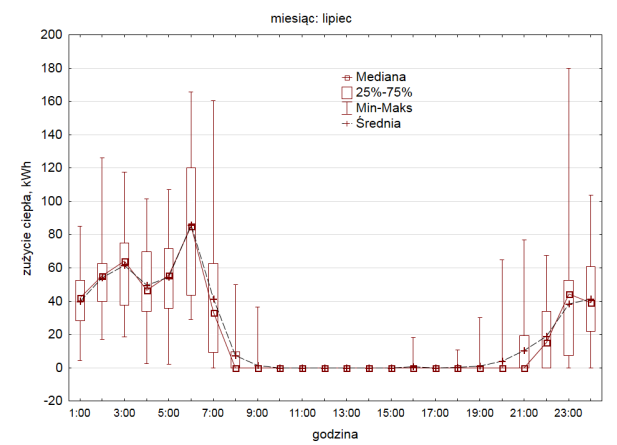

Rys. 8. Wykres ramka-wąsy dla zużycia ciepła w miesiącu lipcu

Fig. 8. Box and whiskers plot for energy consumption in July

Średnie godzinowe wartości obciążeń cieplnych w porze nocnej w miesiącu styczniu kształtują się na poziomie pow. $200 \mathrm{kWh}$, podczas gdy w miesiącu lipcu największa średnia godzinowa wartość nie przekracza $100 \mathrm{kWh}$. W najcieplejszym miesiącu roku, w godzinach od 8:00 do 21:00 większość obserwacji zużycia ciepła jest zerowa i sporadycznie występują przypadki gdy istnieje potrzeba uruchomienia systemu grzewczego.

\section{Wnioski}

Wartości współczynnika maksymalnej mocy grzewczej $L F$ wskazują, że średniomiesięczna zmienność obciążenia systemu grzewczego szklarni waha się $\mathrm{w}$ granicach od $9 \% \mathrm{w}$ czerwcu do $69 \%$ maksymalnej mocy grzewczej w styczniu. W okresie przeprowadzania pomiarów w styczniu zaobserwowano wystąpienie temperatury zewnętrznej poniżej wartości projektowej, a średnie miesięczne temperatury w styczniu i marcu były niższe o ok. $4^{\circ} \mathrm{C}$ od wartości w ty- 
powym roku meteorologicznym. Pozwala to na ocenę obciążenia systemu grzewczego w sytuacjach odstających od projektowych.

Analizę zmienności obciążeń cieplnych systemu grzewczego szklarni z ekranem termoizolacyjnym, zmieniającym właściwości przegrody zewnętrznej obiektu, można dokonywać się na podstawie rzeczywistych pomiarów zużycia ciepła, ponieważ daje to możliwość porównania wyników z zapotrzebowaniem na ciepło, obliczonym np. w oparciu o bilans strumieni ciepła w szklarni. Chwilowe wartości mocy cieplnej wskazywane przez ciepłomierz, z racji na cykliczny dopływ strumienia cieplnego, nie do końca nadają się do budowy wykresu obciążenia cieplnego szklarni z ekranem termoizolacyjnym. W celu właściwej oceny zmienności obciążenia cieplnego sugeruje się korzystanie $\mathrm{z}$ danych rejestrowanych zużycia ciepła z odstępem jednej godziny lub mniejszym.

\section{Literatura}

[1] Grabarczyk S.: Wpływ zastosowania ekranów termoizolacyjnych w obiektach szklarniowych na zużycie energii, Dysertacja, Politechnika Warszawska, Płock 1999.

[2] Tantau H.-J.: Heizungssysteme im Gewachshaus, ITG, Hannover 1982.

[3] Kurpaska S.: Szklarnie i tunele foliowe - inżynieria i procesy, Państwowe Wydawnictwo Rolnicze i Leśne, Poznań 2007.

[4] Wojdyga K.: Prognozowanie zapotrzebowania na ciepło w miejskich systemach ciepłowniczych, Oficyna Wydawnicza Politechniki Warszawskiej, Warszawa 2007.

\section{VARIABILITY OF HEATING LOAD IN GREENHOUSE WITH THERMAL SCREEN}

\section{S u m m a r y}

This paper presents results of investigation of the free-standing greenhouse with movable thermal screen inside. Energy consumption by the modern greenhouse object is analyzed, basing on the in-situ measurements. The aim of these investigation was analysis variability of heating load in greenhouse with thermal screen. The analysis was based on the registration of the external climate parameters, greenhouse microclimate, energy consumption and parameters describing the functioning of the technical equipment of greenhouse.

The computations show that the mean monthly Load Factor is in the range from $9 \%$ in June to $69 \%$ in January. Shows the structure of energy consumption per month with regard to the functioning of the greenhouse with and without a thermal screen as well as its profile changes in cross daily. In analyzes of variability heating load in greenhouse with additional cover it is recommended to use the data about energy consumption or heat demand.

Keywords: greenhouse, thermal screen, heating system, energy consumption, heating load

DOI: $10.7862 / \mathrm{rb} .2016 .260$

Przestano do redakcji: 02.06.2016 r.

Przyjęto do druku: 20.12.2016 r. 